\title{
Variations of the ionospheric TEC using simultaneous measurements from the China Crustal Movement Observation Network
}

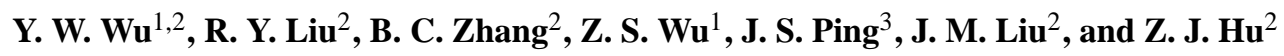 \\ ${ }^{1}$ School of Science, Xidian University, Xi' an, China \\ ${ }^{2}$ SOA Key Laboratory for Polar Science, Polar Research Institute of China, Shanghai, China \\ ${ }^{3}$ Shanghai Astronomical Observatory, Chinese Academy of Sciences, Shanghai, China \\ Correspondence to: Y. W. Wu (wuyewen@pric.gov.cn)
}

Received: 25 November 2011 - Revised: 11 August 2012 - Accepted: 30 August 2012 - Published: 1 October 2012

\begin{abstract}
Variations of the ionospheric Total Electron Content (TEC) over China are investigated using the TEC data obtained from China Crustal Movement Observation Network in the year 2004. The results show a single-peak occurred in post-noon for the diurnal variation and two peaks exit around two equinox points, respectively, for the seasonal variation. Overall, the values of TEC increased from the north to the south of China. There were small but clear longitudinal differences in both sides of the longitudes with zero magnetic declination. The intensity of the day-to-day variation of TEC was not a monotonic change along the latitudes. It was usually weaker in the middle of China than that in the north or south. Comparing with the maximum F-layer electron density $(\mathrm{Nm} \mathrm{F} 2)$ derived from the ionosonde stations in China, it is found that the day-to-day variation of TEC was less significant than that of $N m \mathrm{~F} 2$, and that the northern crest of the equatorial anomaly identified from the $N m \mathrm{~F} 2$ data can reach Guangzhou-region. While, the TEC crest was hardly observed in the same location. This is probably caused by the tilt of topside ionosphere near the northern anomaly crest region at lower latitudes.
\end{abstract}

Keywords. Ionosphere (Equatorial ionosphere; Midlatitude ionosphere)

\section{Introduction}

The ionospheric Total Electron Content (TEC), which has both temporal and spatial variations, is one of the most important ionospheric parameters. The variation of the iono- spheric TEC, for example, can have an apparent influence on radio propagation, especially on earth-space communication and satellite navigation. With observations from the Faraday rotation of a moon-reflected radar (Browne et al., 1956; Evans, 1956, 1974, 1977) and the first satellite, Sputnik 1, significant information on the ionospheric TEC has been obtained (Nisbet, 1960; Nelson, 1968; Evans, 1977).

Recently, due to the wide use of GPS receivers both on satellites at low earth orbit and on the ground, continuous and long-time ionospheric TEC data with increasing accuracy have been obtained and used to analyse the diurnal, seasonal and solar cycle variations of the ionospheric TEC over the Earth (e.g., Breed et al., 1998; Xiao and Zhang, 2000; Stamatis et al., 2004; Yu et al., 2006; Liu and Chen, 2009; Perevalova et al., 2010). Some new parameters, such as the Global Electron Content (GEC) (Afraimovich et al., 2008; Astafyeva et al., 2008) and the global mean TEC (Hocke, 2008, 2009; Liu et al., 2009), have also been derived to track the global characteristics of ionospheric dynamics. It is shown that there are annual variations, semiannual variations and regional variations in terms of TEC, and there is a strong dependence on the solar and geomagnetic activities for the TEC. At the same time, detailed analysis of temporal-spatial TEC variations have been done based on GPS receivers on the ground in some regions, such as in Victoria (Wu et al., 2006), India (Bagiya et al., 2009; Rama Rao et al., 2006) and Salisbury (Breed et al., 1998). Up to now, however, there are only a few papers for the variations of the ionospheric TEC over the whole China region based on direct observations (Huo et al., 2005; Xiao and Zhang, 2000). 
Table 1. Information on the GPS sites and ionosondes used in this work.

\begin{tabular}{llcccc}
\hline ID & City & G-Lat $\left({ }^{\circ} \mathrm{N}\right)$ & G-Lon $\left({ }^{\circ} \mathrm{E}\right)$ & M-Lat $\left({ }^{\circ} \mathrm{N}\right)$ & M-Lon $\left({ }^{\circ} \mathrm{E}\right)$ \\
\hline Hlar* & Hailaer & 49.2 & 119.7 & 43.8 & 192.2 \\
Suiy & Suiyang & 44.4 & 130.9 & 38.4 & 203.0 \\
Urum* & Wulumuqi & 43.8 & 87.6 & 39.2 & 159.9 \\
Wush & Wushi & 41.2 & 79.2 & 36.7 & 151.4 \\
Dxin & Dingxin & 40.9 & 100.1 & 36.0 & 172.3 \\
Bjsh* & Beijing & 40.2 & 116.2 & 34.8 & 188.5 \\
Tash & Tashikuergantajike & 37.7 & 75.2 & 33.1 & 147.5 \\
Yanc & Yanchi & 37.7 & 107.4 & 32.5 & 179.6 \\
Dlha & Delingha & 37.3 & 97.3 & 32.3 & 169.4 \\
Xnin & Xining & 36.6 & 101.7 & 31.4 & 173.8 \\
Tain & Taian & 36.2 & 117.1 & 30.7 & 189.2 \\
Zhnz & Zhengzhou & 34.5 & 113.1 & 29.0 & 185.1 \\
Xiaa & Xi'an & 34.1 & 108.9 & 28.7 & 180.9 \\
Jsgy & Gaoyou & 32.7 & 119.4 & 27.0 & 191.3 \\
Shao & Shanghai & 31.0 & 121.2 & 25.3 & 193.0 \\
Whjf & Wuhan & 30.5 & 114.5 & 24.9 & 186.3 \\
Zjzs & Zhoushan & 30.0 & 122.1 & 24.2 & 193.9 \\
Lhas & Lasa & 29.6 & 91.1 & 24.3 & 163.1 \\
Xiag & Xiaguan & 25.6 & 100.2 & 20.0 & 172.0 \\
Kunm & Kunming & 25.0 & 102.7 & 19.4 & 174.4 \\
Twtf & Taiwan & 24.9 & 121.1 & 19.2 & 192.6 \\
Xiam & Xiamen & 24.4 & 118.0 & 18.7 & 189.5 \\
Guan* & Guangzhou & 23.1 & 113.3 & 17.5 & 184.8 \\
Qion* & Qiongzhong & 19.0 & 109.8 & 13.6 & 181.3 \\
Yong & Yongxing & 16.8 & 112.3 & 11.7 & 183.7 \\
\hline
\end{tabular}

“*” stands for the GPS site where there is an ionosonde nearby.

G: Geographical co-ordinate; M: Geomagnetic co-ordinate; Lat: Latitude; Lon: Longitude

Since V. Appleton (1946) and Liang (1947) found an equatorial anomaly, based on data of ionospheric critical frequencies, much work about this phenomenon has been done. Compared to the data of $f_{o} \mathrm{~F} 2$, the latitudinal distribution of the ionospheric TEC shows a similar structure to the maximum electron density of the ionosphere (Huang et al., 1987). This means that the equatorial anomaly can also be found using TEC data. Huang et al. (1989) also pointed out that the location of the equatorial anomaly crest determined by either TEC or $f o F 2$ always varies with not only season, but also the time of the day. Stamatis et al. (2004) showed that the day-today variation for TEC lies between those of $f o \mathrm{~F} 2$ and $N m \mathrm{~F} 2$, depending on the level of solar activity.

In this paper, the diurnal, seasonal and day-to-day variations of the ionospheric TEC over China were investigated, based on the vertical TEC (VTEC) data from 25 GPS receiver sites from China Crustal Movement Observation Network in 2004. Combining the $f_{o} \mathrm{~F} 2$ data, the day-to-day variations are examined for the TEC and the $N m \mathrm{~F} 2$, and the location of the equatorial anomaly crest identified by the TEC is compared with that by the NmF2 data. Possible mechanisms for the observed behaviours are discussed.

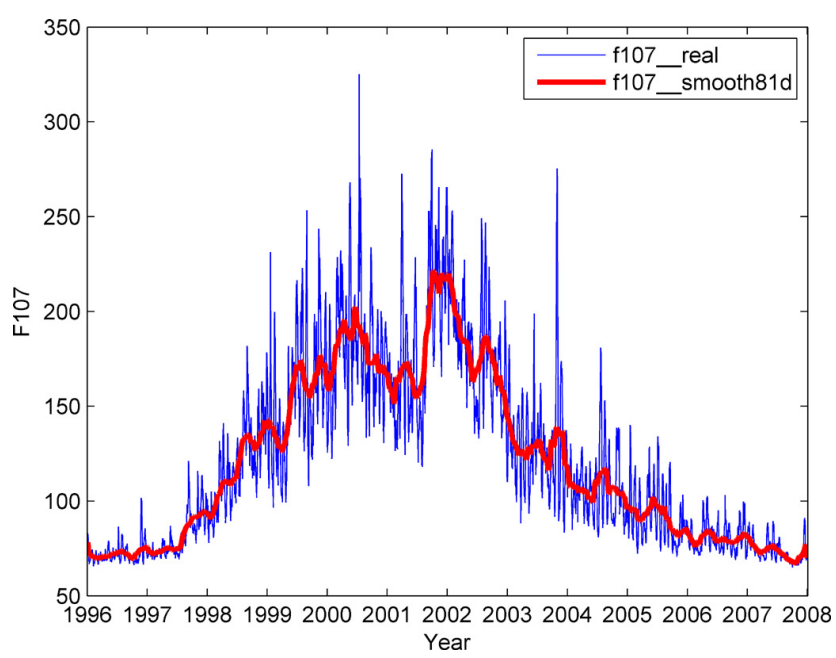

Fig. 1. The variation of F107 index from 1996 to 2007.

\section{Data}

Table 1 shows the locations of the sites we used, including 25 GPS receiver sites in China Crustal Movement Observation Network and 5 ionosondes stations, where the "** stands for the GPS site with an ionosonde nearby. All sites 

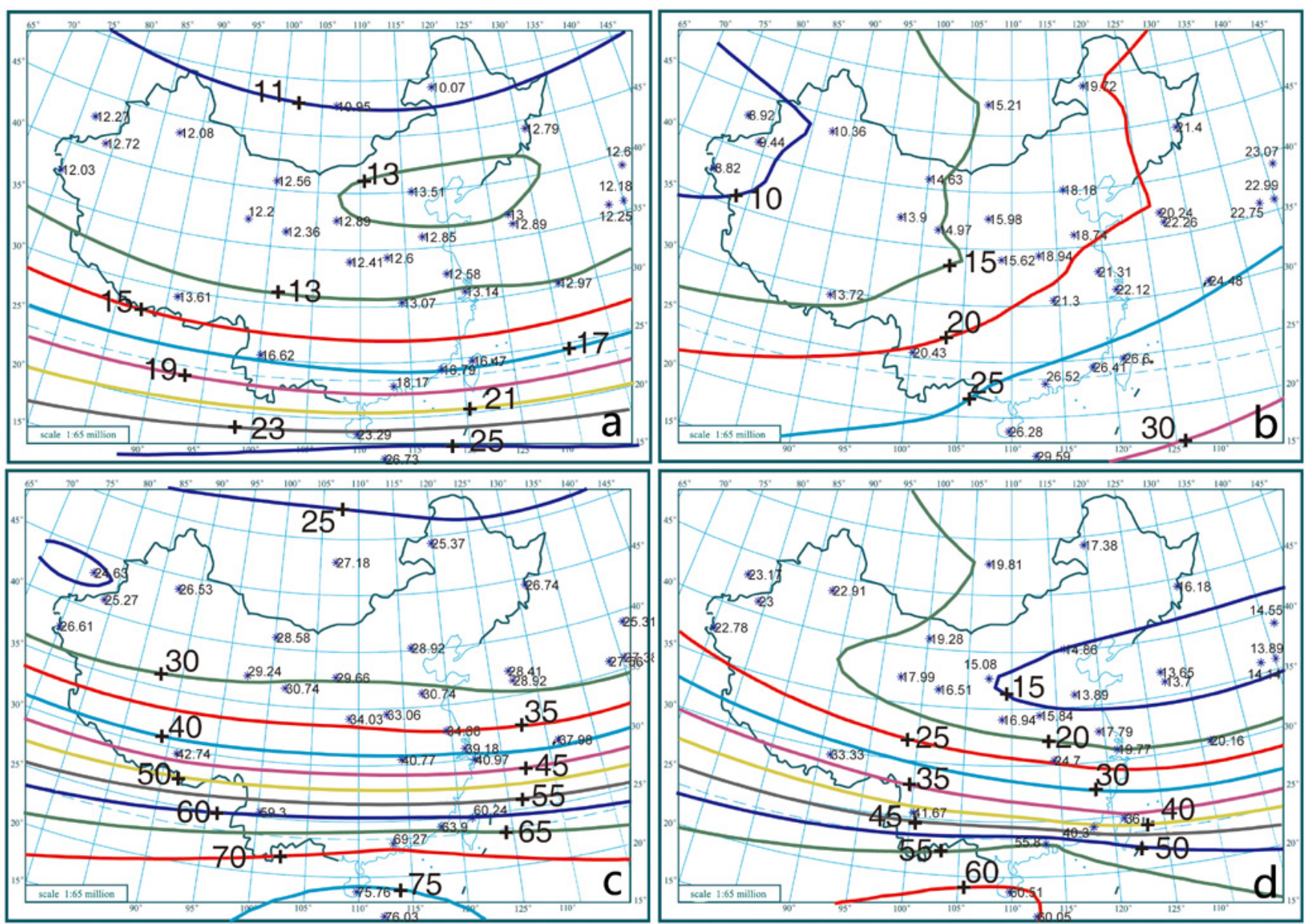

Fig. 2. TEC contour maps over China at four times on 20 March 2004. Unit: TECu. (a) 02:00 BST; (b) 08:00 BST; (c) 14:00 BST; (d) 20:00 BST.

run routinely. From Table 1, we can see that the GPS sites cover the whole China region. Therefore, the variable characteristics of the ionospheric TEC over China can be described based on the TEC data here.

The TEC data are calculated using the method as described by Zhang et al. (2008) and Xue et al. (2012). The equations of the GPS P code observation are given as follows:

$P_{1 j}^{i}=\rho_{j}^{i}+c\left(d t^{i}-d t_{j}\right)+d_{\mathrm{tropj}}^{i}+d_{\mathrm{ion} 1 \mathrm{j}}^{i}+d q_{1 j}+d q_{1}^{i}$

$P_{2 j}^{i}=\rho_{j}^{i}+c\left(d t^{i}-d t_{j}\right)+d_{\text {tropj }}^{i}+d_{\text {ion } 2 \mathrm{j}}^{i}+d q_{2 j}+d q_{2}^{i}$

where $P_{1 j}^{i}$ and $P_{2 j}^{i}$ are the dual-frequency P-code pseudorange observational quantities, $\rho_{j}^{i}$ is the distance from the $i$ th satellite to the $j$-th station, $c$ is the velocity of light in the vacuum, $d t^{i}$ and $d t_{j}$ are, respectively, the clock bias of the satellite and receiver, $d_{\text {tropj }}^{i}$ is the tropospheric delay, $d_{\text {ionkj }}^{i}$, $d q_{k j}$ and $d q_{k}^{i}$ are the ionospheric delay, the GPS receiver hardware delay and the satellite hardware delay at two different frequencies $(k=1,2)$, respectively. For a high-frequency system, such as GPS, we just consider 1st-order series ex- pression of the ionospheric delay as Eq. (2).

$d_{\text {ion }}=40.28 \frac{\text { TEC }}{f^{2}}$

in which, TEC is the ionospheric total electron content along the signal path, in units of $\mathrm{el} \mathrm{m}^{-2}, f$ is the signal frequency in units of $\mathrm{Hz}$ and $d_{\mathrm{ion}}$ is expressed in units of metres. Making the difference between two observed values of P-code pseudorange in Eq. (1) and introducing Eq. (2), we can obtain the TEC along the path from the station to the satellite as follows:

$\mathrm{TEC}=9.52437\left(P_{2 j}^{i}-P_{1 j}^{i}-\left(d q_{2 j}-d q_{1 j}\right)-\left(d q_{2}^{i}-d q_{1}^{i}\right)\right)$

The TEC in Eq. (3) is slant TEC (STEC). The elevation angles are limited in a range larger than $10^{\circ}$ in data handling. Adopting the multinominal expansion model of single-layer ionosphere $(450 \mathrm{~km})$ and the projection function of cosine, we can obtain the vertical TEC (VTEC) at the station and 


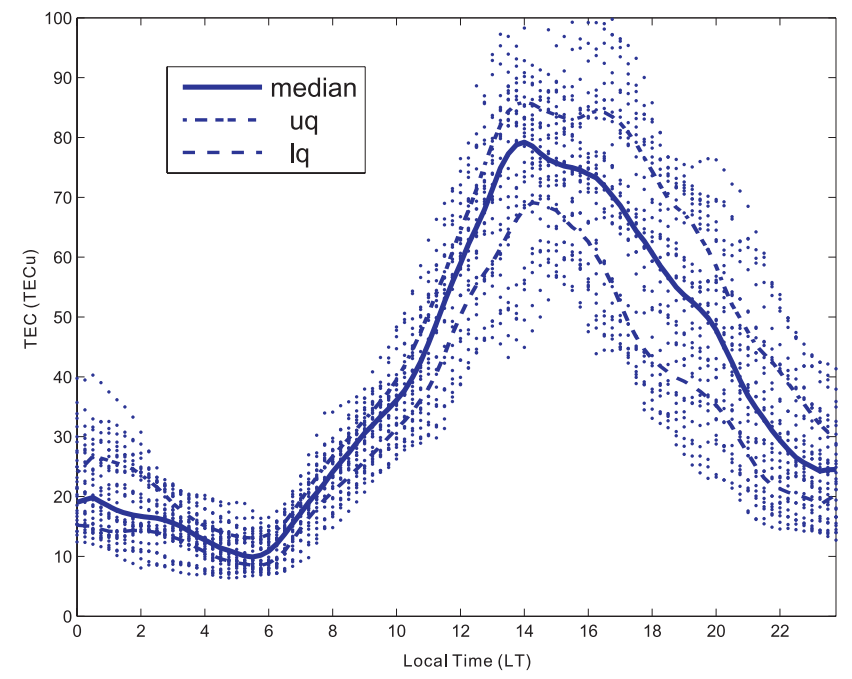

Fig. 3. Diurnal variations of TEC at Guangzhou (Guan) in March 2004 (the solid line is the median TEC value, the dotted one is the UQ value and the dashed one is the LQ).

the hardware delays. Applying this method for Chinese GPS regional network, the relative accuracies and RMS of the quasi-realtime VTEC can reach $2.0 \mathrm{TECu}$ and $1.925 \mathrm{TECu}$, respectively (Xue et al., 2012). The sample rate of the STEC, namely the TEC in Eq. (3), is 30 s. The VTEC at GPS site is averaged every $15 \mathrm{~min}$ and then used in this paper.

The TEC 2004 data are considered, when it is in the declining phase of the 22th solar cycle. This can be seen clearly from Fig. 1, showing the variation of the F107 index from 1996 to 2007. The blue line denotes the daily F107 index, and the red line is the smoothed F107 index with a window of 81 days. The F107 index in 2004 is larger than 90 and less than 120.

\section{Variations of ionospheric TEC}

Based on the averaged TEC data above, the TEC contour maps over China were derived using the corrected Kriging method (Liu et al., 2008). As an example, TEC contours at four different times on 20 March 2004 (a: 02:00 BST; b: 08:00 BST; c: 14:00 BST and d: 20:00 BST) are shown in Fig. 2, where "**" stands for the GPS site, and the numbers are the TEC values in units of TECu $\left(1 \mathrm{TECu}=1 \times 10^{16} \mathrm{el} \mathrm{m}^{-2}\right)$. The F107 index is 112.7 and the Ap index is 6, 12, 4 and 7 for a, b, c and d, respectively. BST stands for Beijing Standard Time, which equals to UT (universal time) added by $8 \mathrm{~h}$. It can be seen that there are sunrise and sunset effects shown in Fig. 2b and Fig. 2d, respectively. As a whole, the TEC have the largest value at 14:00 BST and the smallest value at 02:00 BST. The TEC values increase from the north to the south of China. The diurnal variation, the seasonal variation and the day-to-day variation of the ionospheric TEC over China are studied as follows.

\subsection{Diurnal variation of TEC}

The characteristics of diurnal variation of TEC are investigated in terms of median, upper-quartile (uq) and lowerquartile (lq) of TEC for one month. As an example, Fig. 3 shows the diurnal variation of TEC at Guangzhou (Guan) in March. It can be clearly seen that there is an obvious singlepeak with a value of about $80 \mathrm{TECu}$ around 14:00 LT and a short-lived pre-dawn minimum of about $10 \mathrm{TECu}$. This pattern of diurnal variation is similar to those over the same region both in 1998 (Xiao and Zhang, 2000) and 2001 (Huo et al., 2005) as well as over the other places (e.g., Chauhan et al., 2011; Gupta and Singh, 2000). Furthermore, the diurnal variations of the TEC data from 6 GPS sites along $120^{\circ} \mathrm{E}$ are also investigated. The results are shown in Fig. 4, where the columns show the diurnal variation in spring, summer, autumn and winter, and rows present the TEC data from Hlar, Bjsh, Tain, Whjf, Guan and Qion, respectively. These sites are sorted in turn by their geographical latitude from higher to lower. We take Guan as an example again, which is displayed in the fifth row of Fig. 4 from the top, to analyse the diurnal variation. It can be seen that an obvious peak exists in each month. The TEC peaked at $\sim 60 \mathrm{TECu}$ in September and $\sim 50 \mathrm{TECu}$ both in June and December. These values are lower than the peak values in March, says near $80 \mathrm{TECu}$. At the other sites, the TEC also shows a single peak in the post noon, with the peak value in vernal and autumnal equinoxes are generally higher than in summer and winter. The single peak structures at higher latitudes are not as sharp as those at low latitudes, especially in June. In addition, the peaks at lower latitudes appeared later than those at the higher latitudes in the same month. While for the same site, the peaks in June occur later ( 16:00 LT) than in other months ( 14:00 LT).

Furthermore, it is worth noting that the peak value in winter was a little lower than in summer, which means that there was no winter anomaly in 2004. This is different from the observations in 2001 shown by Huo et al. (2005), which was interpreted to be caused by the difference of solar activity between these two years. Solar activity in 2004 was at a declining phase, while at the solar maximum phase in 2001, as shown in Fig. 1.

From the east to the west of China, the diurnal variations of the TEC over 4 GPS receiver sites along $\sim 40^{\circ} \mathrm{N}$ are investigated, as shown in Fig. 5. The 4 GPS receiver sites are Mizu, Bjsh, Dxin and Wush, respectively. Here, data from one Japanese GPS site at Mizusawa (Mizu, $141.1^{\circ} \mathrm{E}$, $39.1^{\circ} \mathrm{N}$ ) are used. Generally speaking, it can be found from Fig. 5 that the diurnal variations are very similar among the four stations, indicating that the longitudinal variation of TEC could be described as LT variation in the first order. Examining Fig. 5, we do notice clear longitudinal differences. The times of the daily peaks occurred later on the east-most sites than on the west sites. The daytime density is normally lower in the east-most site than in the west site, and this turns 


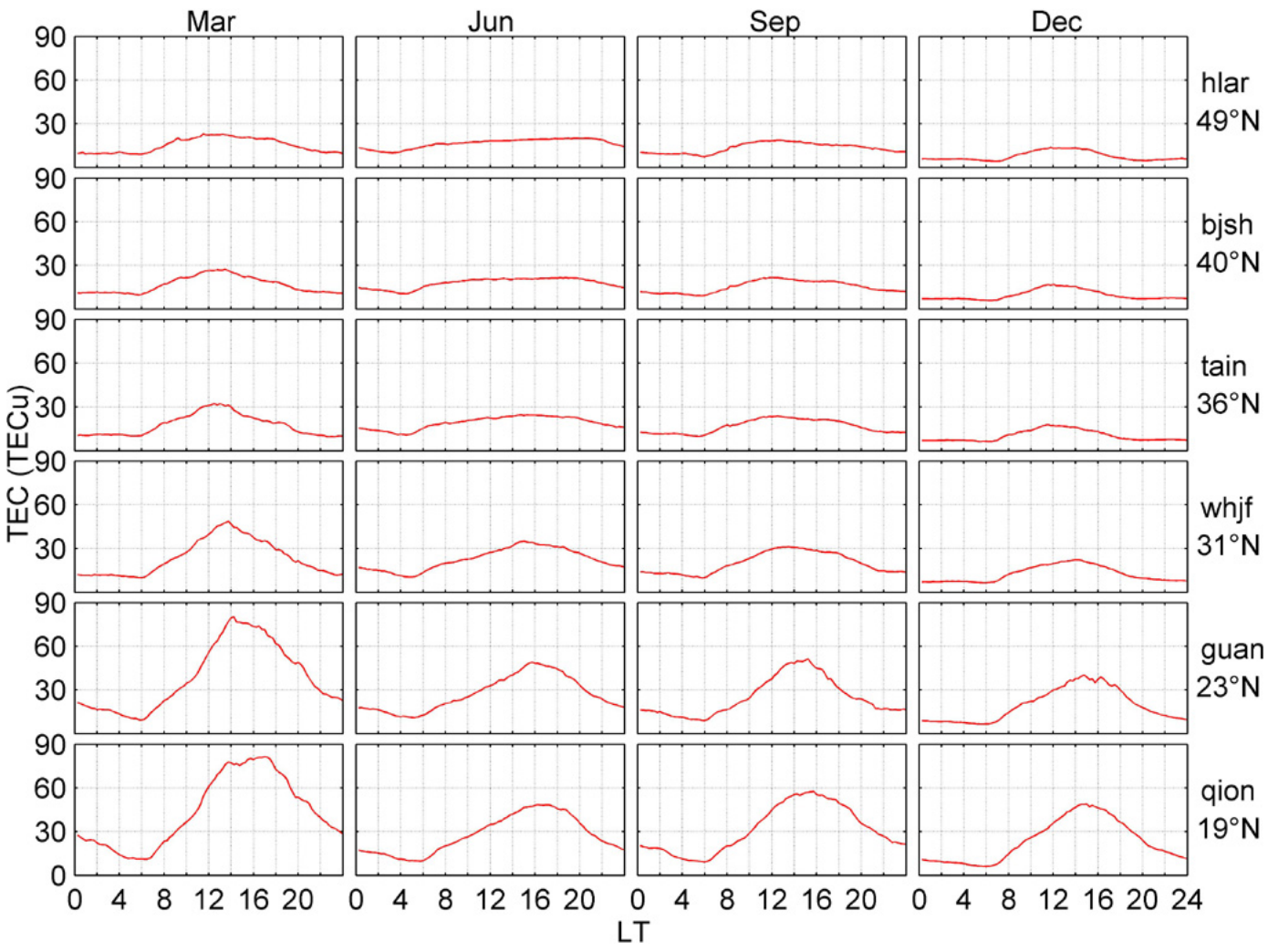

Fig. 4. Diurnal variations of TEC (median) in four months (March, June, September and December) in 2004 at 6 GPS sites along $120^{\circ}$ E.

opposite during the nighttime. These results agree well with the recent studies (Zhang et al., 2011, 2012). These longitudinal differences are caused by the difference in magnetic declination which gives rise to upward and downward ion drifts across the zero declination for a given thermospheric zonal wind direction. In China region, the magnetic declination is westward (negative) on the east side of China and eastward (positive) on the west side, with zero value along $\sim 100^{\circ} \mathrm{E}$ longitude. Both Mizu and Bjsh are located east of $100^{\circ} \mathrm{E}$, while Dxin is $100^{\circ} \mathrm{E}$ and Wush is located west of $100^{\circ}$ E. Here, the TEC observations confirm that the longitudinal differences occurred over China region, too.

\subsection{Seasonal variation of TEC}

Some seasonal variations of TEC have been discussed in the above section using the monthly median values. In this section, the monthly grand-mean $\left(\mathrm{TEC}_{\text {mean }}\right)$ and the monthly grand-variation intensity $\left(\mathrm{TEC}_{\text {intensity }}\right)$ are introduced to study overall properties of TEC seasonal variation. $\mathrm{TEC}_{\text {mean }}$ and $\mathrm{TEC}_{\text {intensity }}$ are computed by Eqs. (4) and (5), respectively.

$\mathrm{TEC}_{\text {mean }}=\frac{1}{96 \times D} \sum_{\text {day }=1}^{D} \sum_{i=1}^{96} \mathrm{TEC}_{\mathrm{day}, i}$
$\mathrm{TEC}_{\text {intensity }}=\sqrt{\frac{1}{96 \times D}\left[\sum_{\text {day }=1}^{D} \sum_{i=1}^{96}\left(\mathrm{TEC}_{\text {day }, i}-\mathrm{TEC}_{\text {mean }}\right)^{2}\right]}$

where $D$ is the number of the day in one month, 96 is the number of the TEC data in one day.

As shown in Sect. 3.1, we choose the six sites along $120^{\circ} \mathrm{E}$ and the four sites along $40^{\circ} \mathrm{N}$ to investigate the seasonal variation of TEC over the China region. Figure 6 shows both the $\mathrm{TEC}_{\text {mean }}$ and the $\mathrm{TEC}_{\text {intensity }}$ at the six sites (same as in Fig. 4) along $120^{\circ} \mathrm{E}$. It can be found that, for the two parameters, there are two peaks at the equinoxes at all sites, which are the same as the results of the previous researches (e.g., Huang et al., 1989; Tsai et al., 2001). The values were higher and the double peak structure was more obvious at the low latitudes, which were similar to the seasonal variation of the maximum electron density (e.g., Zhang et al., 2005; Liu et al., 2009; and references therein).

Figure 7 shows both the $\mathrm{TEC}_{\text {mean }}$ and the $\mathrm{TEC}_{\text {intensity }}$ at the four sites (same as in Fig. 5) along $40^{\circ} \mathrm{N}$. We can see that they are almost the same values and the same variations, which indicates that the longitudinal differences are much smaller than latitudinal differences. This trend implies that 


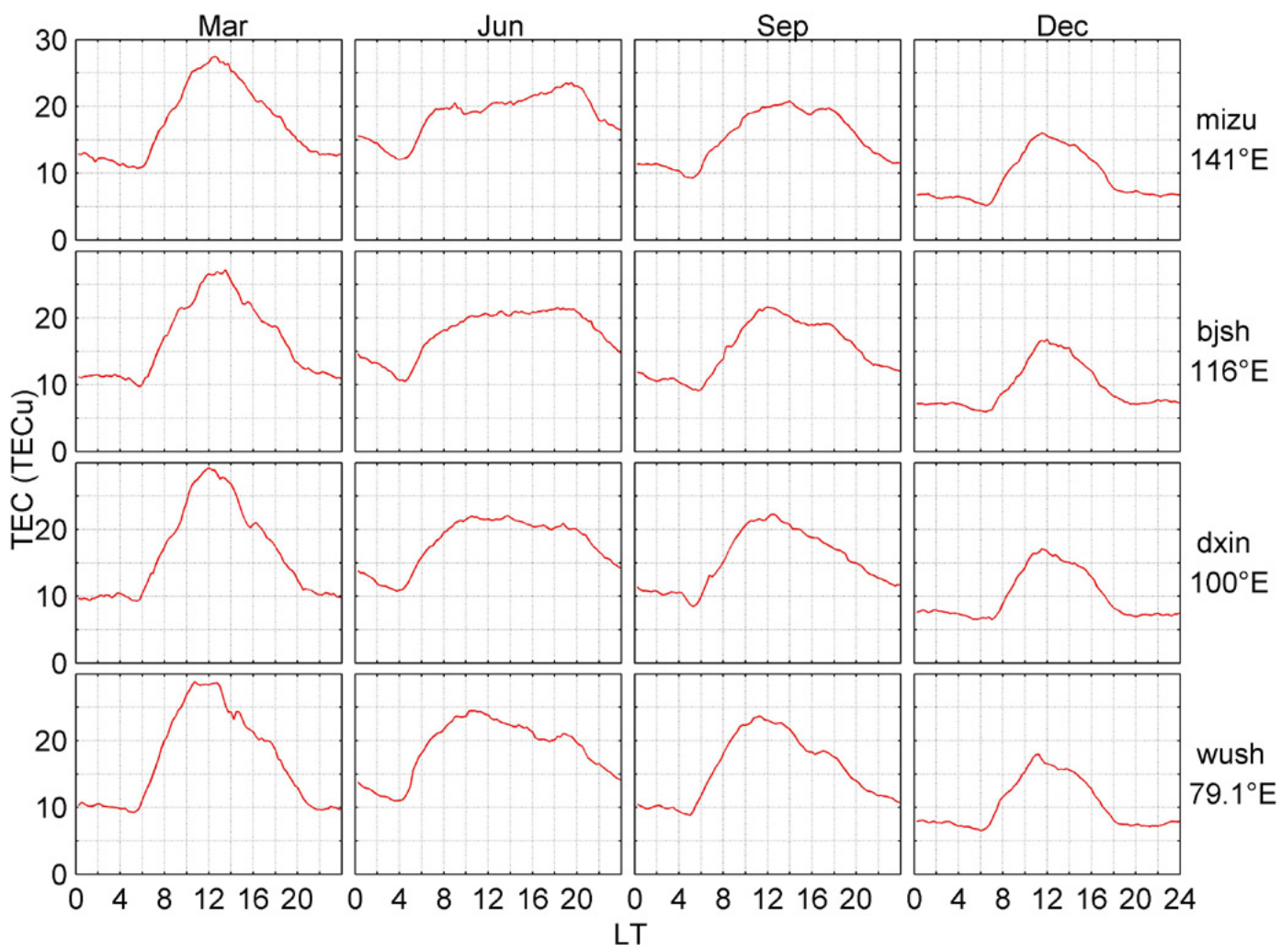

Fig. 5. Diurnal variations of TEC (median) in four months (March, June, September and December) in 2004 at 4 GPS sites along $40^{\circ}$ N.

Table 2. The mean value of $U, L, R$ and $K$ of TEC in 2004.

\begin{tabular}{cccccc}
\hline & Hlar & Bjsh & Urum & Guan & Qion \\
\hline$U$ & 0.152 & 0.127 & 0.133 & 0.164 & 0.155 \\
$L$ & 0.135 & 0.109 & 0.104 & 0.128 & 0.122 \\
$R$ & 0.287 & 0.236 & 0.236 & 0.292 & 0.277 \\
$K$ & 1.318 & 1.236 & 1.450 & 1.434 & 1.390 \\
\hline
\end{tabular}

not only the $\mathrm{TEC}_{\text {mean }}$, but also the $\mathrm{TEC}_{\text {intensity }}$ as a whole mainly varied with the latitude. The lower latitude, the larger values of these two parameters.

\subsection{Day-to-day variation}

Four parameters are introduced to describe the day-to-day variation of TEC. They are relative upper-quartile $(U)$, lower-quartile $(L)$, relative range of quartiles $(R)$ and ratio of upper and lower quartiles $(K)$, and are defined by Eqs. (6)(9), respectively.

$U_{(i)}=\frac{\mathrm{uq}_{(i)}-\operatorname{median}_{(i)}}{\operatorname{median}_{(i)}}$

$L_{(i)}=\frac{\operatorname{median}_{(i)}-\mathrm{lq}_{(i)}}{\operatorname{median}_{(i)}}$

$$
\begin{aligned}
& R_{(i)}=U_{(i)}+L_{(i)}=\frac{\mathrm{uq}_{(i)}-\mathrm{lq}_{(i)}}{\operatorname{median}(i)} \\
& K_{(i)}=\frac{U_{(i)}}{L_{(i)}}=\frac{\mathrm{uq}_{(i)}-\operatorname{median}_{(i)}}{\operatorname{median}_{(i)}-\operatorname{lq}_{(i)}}
\end{aligned}
$$

Here the $\operatorname{median}_{(i)}, \mathrm{uq}_{(i)}$ and $\mathrm{lq}_{(i)}$ denote the median value, the upper quartile and the lower quartile of TEC at time $i$ in one month, respectively. The mean values of these parameters for all times in 2004 are shown in Table 2 for 5 sites (Hlar $\left(49.2^{\circ} \mathrm{N}, 119.7^{\circ} \mathrm{E}\right), \operatorname{Bjsh}\left(40.2^{\circ} \mathrm{N}, 116.2^{\circ} \mathrm{E}\right)$, Urum $\left(43.8^{\circ} \mathrm{N}, 87.6^{\circ} \mathrm{E}\right)$, Guan $\left(23.1^{\circ} \mathrm{N}, 113.3^{\circ} \mathrm{E}\right)$, Qion $\left(19^{\circ} \mathrm{N}\right.$, $\left.109.8^{\circ} \mathrm{E}\right)$ ). It can be seen that the $U, L$ and $R$ parameters had smaller values in the middle region of China, such as Bjsh and Urum. It means that the intensity of the TEC dayto-day variation was not a monotonic change along the latitudes. It was usually weaker in the middle of China than that in the north or south. In addition, the mean of the parameter $K$ was larger than 1, which indicates that the distribution of TEC was asymmetric and the upper half of distribution is more dispersed than the lower half. 

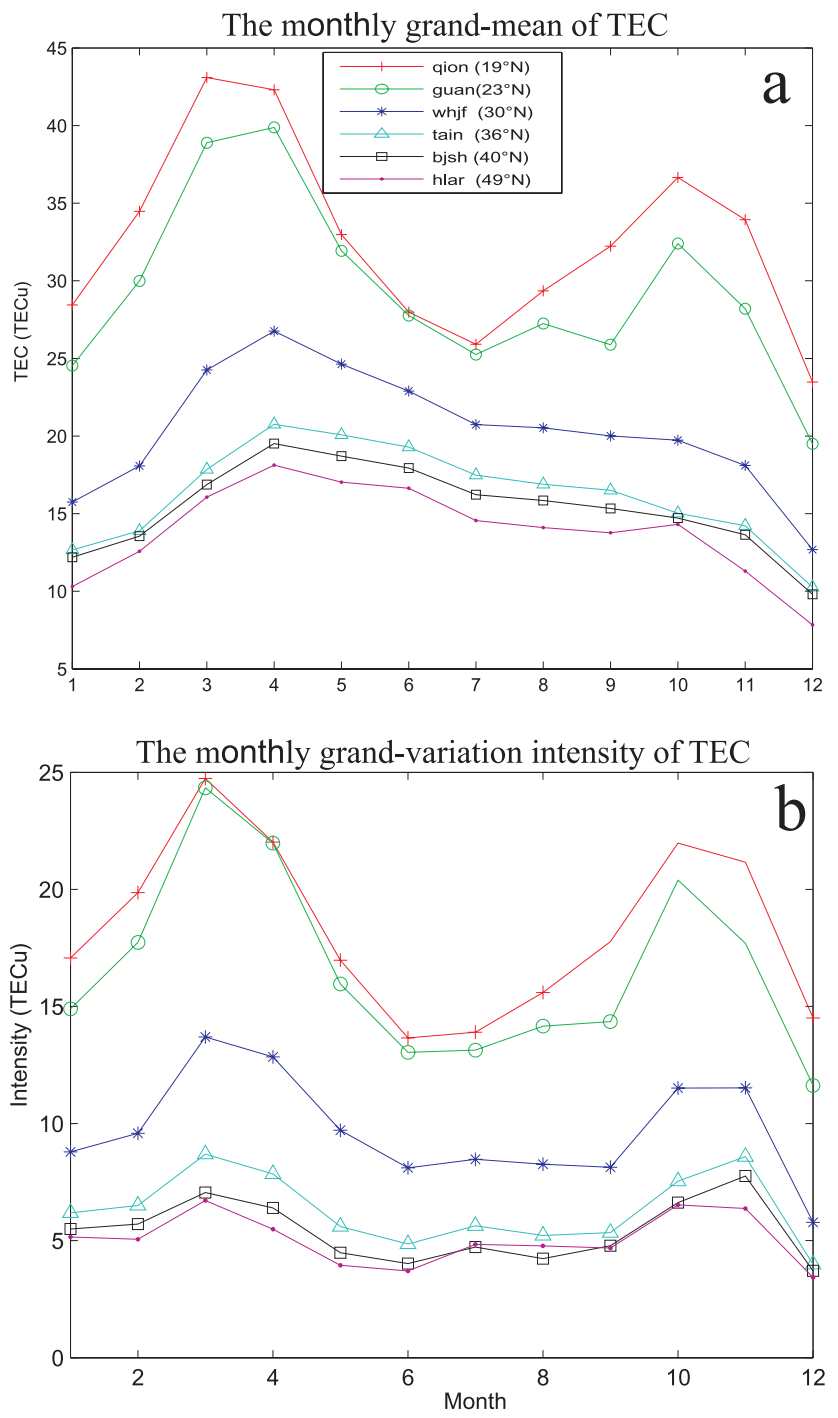

Fig. 6. Seasonal variations of the monthly grand-mean (a) and the monthly grand-variation intensity (b) of TEC at six GPS sites along $120^{\circ} \mathrm{E}$.

\section{Disscussion}

In China, there are 11 ionosonde sites all together, from which we can get continuous and accurate ionospheric parameters, such as $f o \mathrm{~F} 2$. Among them, 5 ionosonde sites are close to the GPS sites, which are shown in Table 1 with "*”. From $f o \mathrm{~F} 2$, the $N m \mathrm{~F} 2$ can be computed using Eq. (10).

$N m \mathrm{~F} 2=\frac{f o \mathrm{~F} 2^{2}}{81}$

where the units of $f o \mathrm{~F} 2$ and $\mathrm{NmF} 2$ are $\mathrm{Hz}$ and el m${ }^{-3}$, respectively.

The discussion below is based on TEC and $N m F 2$ data, focusing on the ionospheric day-to-day variation and the location of equatorial anomaly crest.
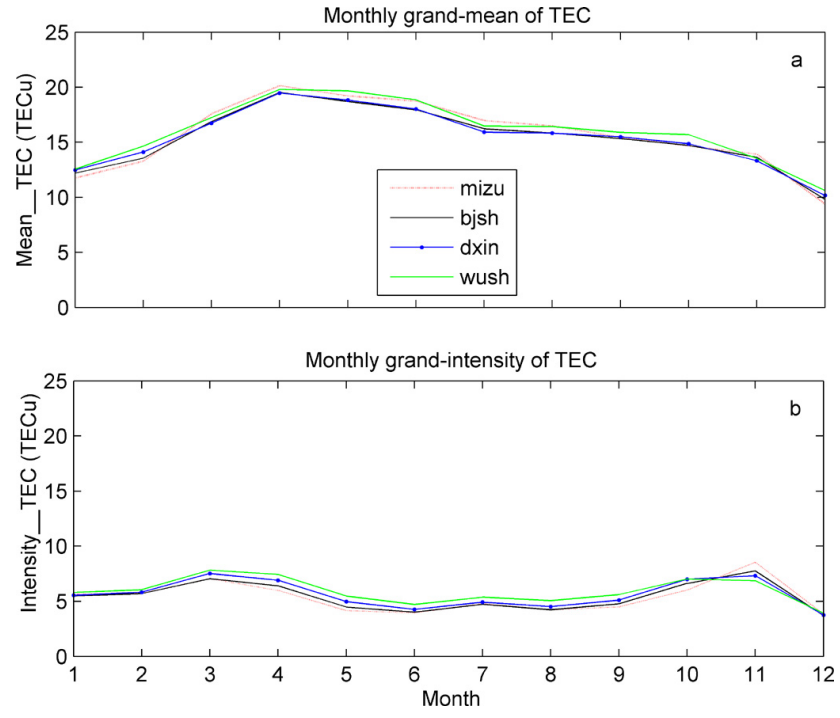

Fig. 7. Seasonal variations of the monthly grand-mean (a) and the monthly grand-variation intensity (b) of TEC at four GPS sites along $40^{\circ} \mathrm{N}$.

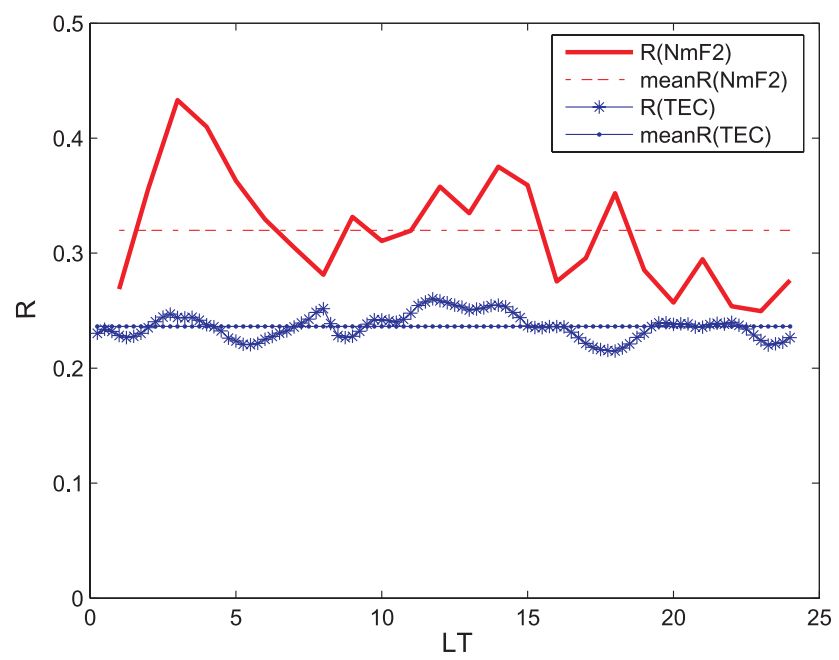

Fig. 8. Relative ranges of day-to-day variations of both TEC and $N m \mathrm{~F} 2$ with $\mathrm{LT}$ at Beijing.

\subsection{Comparison of day-to-day variation between TEC and $\mathrm{NmF2}$}

The day-to-day variation of TEC has been investigated with the parameters of $U, L, R$ and $K$. Inserting the uq, lq and median value of $N m \mathrm{~F} 2$ into Eqs. (6)-(9), these parameters for the day-to-day variation of $N m \mathrm{~F} 2$ were also obtained and shown in Table 3. It can be seen that the values of TEC's $U, L$ and $R$ are usually smaller than those of $N m \mathrm{~F} 2$, respectively. This is because the TEC is an integral parameter of electron density at all altitudes, while the $N m \mathrm{~F} 2$ is just the electron density at a particular altitude. The variation of TEC, subsequently, is usually weaker than that of $N m \mathrm{~F} 2$. For the 


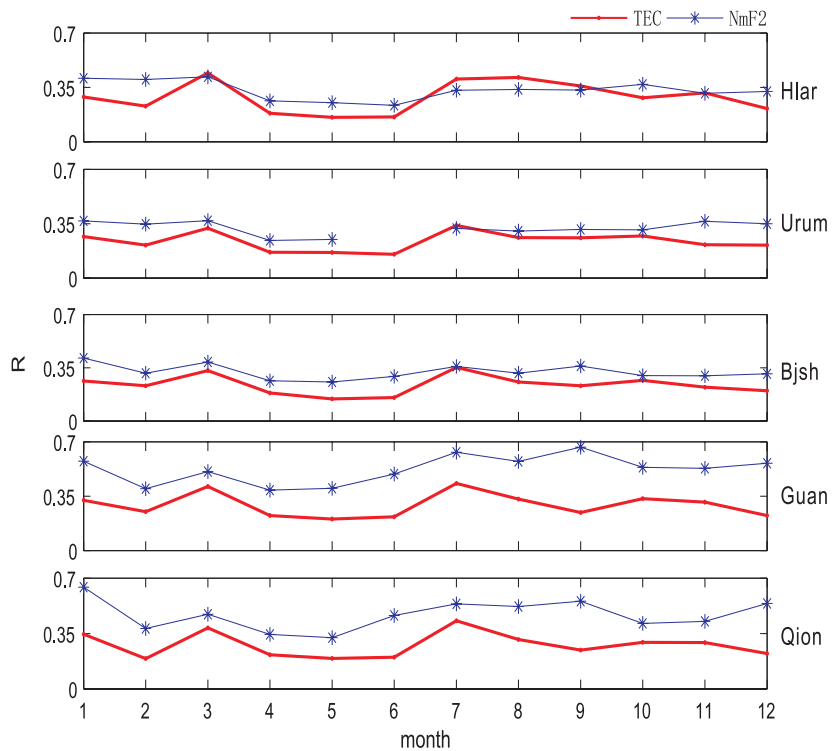

Fig. 9. Relative ranges of day-to-day variations with month for both TEC and $N m$ F2.

Table 3. The mean value of $U, L, R$ and $K$ of $N m \mathrm{~F} 2$ in 2004.

\begin{tabular}{cccccc}
\hline & Hlar & Bjsh & Urum & Guan & Qion \\
\hline$U$ & 0.168 & 0.167 & 0.176 & 0.297 & 0.258 \\
$L$ & 0.163 & 0.153 & 0.146 & 0.225 & 0.210 \\
$R$ & 0.331 & 0.320 & 0.321 & 0.522 & 0.468 \\
$K$ & 1.171 & 1.304 & 1.412 & 1.541 & 1.362 \\
\hline
\end{tabular}

parameter of $K$, however, there is no distinct relationship between TEC and $N m \mathrm{~F} 2$.

Besides, some detail comparisons of the day-to-day variation between TEC and $N m \mathrm{~F} 2$ were also investigated by taking the $R$ value as an example. Figure 8 shows the variation of $R$ with LT at Beijing in 2004. It can be found that the mean of $R$ of TEC (0.24) is less than that of $N m F 2(0.32)$, and the $R$ of TEC fluctuates around their mean value more weakly than the $R$ of $N m \mathrm{~F} 2$ does. At other sites, the $R$ varies in a similar way. Figure 9 shows the seasonal variation of $R$ at the 5 sites. It shows clearly that, except a few months at Hlar, the $R$ values of TEC are always smaller than those of $N m \mathrm{~F} 2$, especially at Guan and Qion. It is worth noting that there are two peaks of $R$ of TEC occurring in March and July, respectively.

\subsection{Location of equatorial anomaly crest}

It is well known that the low-latitude region of China is influenced by the equatorial anomaly (e.g., Liang, 1947). In the past, however, the location of the equatorial anomaly crest was determined based on $f_{o} \mathrm{~F} 2$ or $N m \mathrm{~F} 2$. In the south of China, there are 2 ionosondes at Guangzhou and Haikou, respectively, and Haikou $\left(20.2^{\circ} \mathrm{N}, 110.3^{\circ} \mathrm{E}\right)$ is very close to
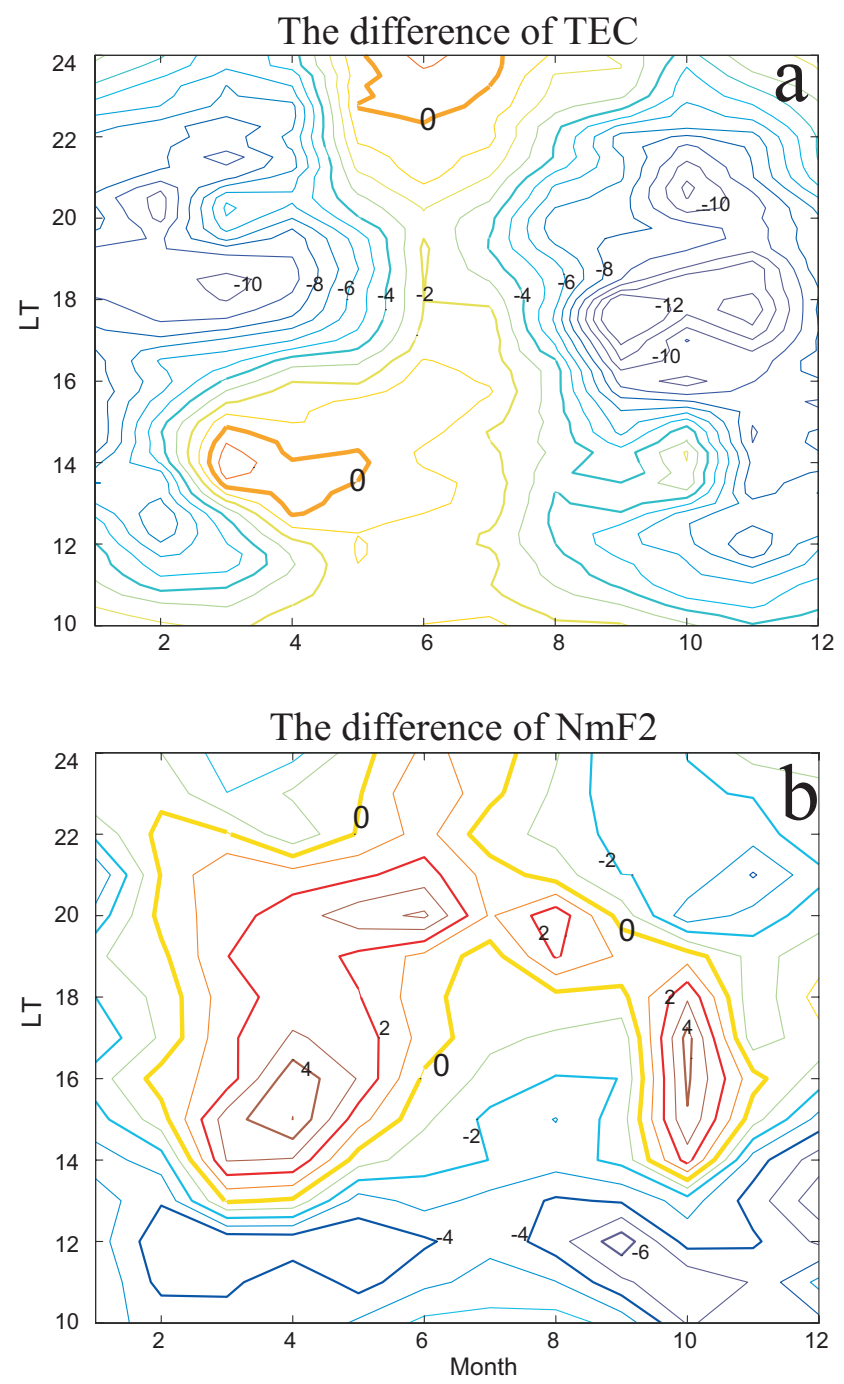

Fig. 10. (a) Contour map of the TEC differences between Guangzhou and Qiongzhong in 2004 (unit: TECu). (b) Contour map of the $N m$ F2 differences between Guangzhou and Haikou in 2004 (unit: $10^{11} \mathrm{el} \mathrm{m}^{-3}$ ).

Qiongzhong $\left(19^{\circ} \mathrm{N}, 109.8^{\circ} \mathrm{E}\right)$ where there are GPS observations. Therefore, the location of equatorial anomaly crests in the south of China can be analysed in terms of the differences of TEC values between Guangzhou and Qiongzhong and the differences of $N m \mathrm{~F} 2$ values between Guangzhou and Haikou, respectively.

Since it is believed that Guangzhou, with a magnetic latitude of 17.5 , is very close to the northern crest of the equatorial ionization anomaly, it is assumed that if the difference is positive, the crest may reach Guangzhou or somewhere toward the north of Guangzhou; if the difference is negative, the crest may just reach Qiongzhong or somewhere around Qiongzhong, but further away from Guangzhou.

The differences for different months and local times are shown in Fig. 10. Figure 10a shows that the TEC values at 


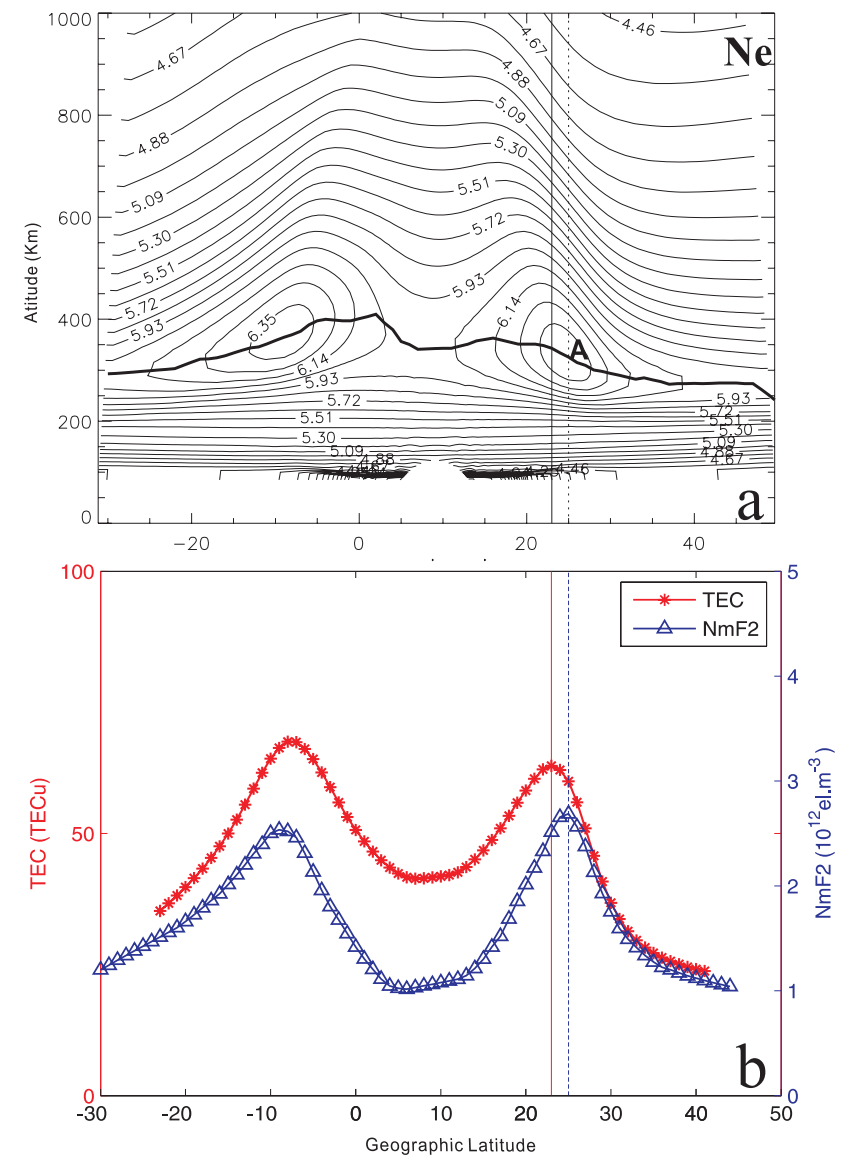

Fig. 11. (a) Distribution of the electron density derived from the Sami2 Model at 15:00 LT, 1 October 2004 (unit: $\log (\mathrm{Ne}) \mathrm{cm}^{-3}$ ). (b) Distribution of TEC and $N m \mathrm{~F} 2$ based on the simulative data of Sami2 Model at 15:00 LT, 1 October 2004.

Guangzhou are larger than that in Qiongzhong only around 14:00 LT in March and April, while in the other months in the post noon, TEC values at Guangzhou are smaller than that at Qiongzhong, especially in winter and equinoxes. However, the $N m \mathrm{~F} 2$ values at Guangzhou are usually lager than that at Haikou except for the period of time around 16:00 LT in July (see Fig. 10b). It suggests that the $N m \mathrm{~F} 2$ crest could reach the region around Guangzhou usually, but the TEC crest can be hardly observed in Guangzhou.

This phenomenon could be explained by using the theoretical model named Sami2 (Huba et al., 2000), which is a low-latitude model of ionosphere, developed by the Naval Research Laboratory (NRL). It is the first low-latitude ionospheric model including the ion inertial terms in the momentum equations. The neutral species are specified using the Mass Spectrometer Incoherent Scatter model (MSIS86) and the Horizontal Wind Model (HWM93). The daytime photoionization model uses the solar EUV flux model for aeronomic calculations (EUVAC) developed by Richards et al. (1994). The nighttime photoionization model uses the so- lar EUV flux prescribed by Strobel et al. (1974) and the photoionization cross-sections are obtained from Oran et al. (1974). The electron density in the ionosphere at 15:00 LT on 1 October 2004 is calculated by Sami2, with the Ap index 3 and F107 index 88.1, and the average of F107 index for the 3 months is 113.8. Based on the simulated results from Sami2, the ionospheric TEC, $N m F 2$ and the peak height of the F2 layer $(h m \mathrm{~F} 2)$ were also calculated. The first two parameters are shown in Fig. 11b, while the last one is shown in Fig. 11a by the heavy line. Here, we take Guan as an example again to check the Sami2 model over the China region. The TEC value from the Sami2 model is $62.9 \mathrm{TECu}$ at $23^{\circ} \mathrm{N}$ at 15:00 LT in March 2004. It is very close to the TEC value of the observation, which is $63.1 \mathrm{TECu}$ at Guan $\left(23.1^{\circ} \mathrm{N}\right)$ at the same time. This indicates that the Sami2 model is valid for this particular simulation.

The results show that the location of the crest identified by TEC (the solid vertical line in Fig. 11b) is different from that determined by $N m \mathrm{~F} 2$ (the dotted vertical line in Fig. 11b). The location of TEC crest is closer to the equator. This phenomenon can be interpreted to the tilt of the topside ionosphere near the anomaly crest region. At the altitudes above $h m \mathrm{~F} 2$ (given by the heavy line in Fig. 11a), the distribution of ionospheric electron density tilts down with latitude, so that, at the same altitude, the electron density at the latitude where $N m \mathrm{~F} 2$ crest locates (A) is smaller than that at latitudes closer to equator. So the TEC which is integral along the altitude at the latitude of "A" is smaller than the TEC at the lower latitudes.

The tilt of the topside ionosphere is caused by the fountain effects (Martyn, 1947, 1953). With an eastward electric field, the plasma in the equator drifts upward to a higher altitude, then diffuses and descends to higher latitudes. At the same time, the magnetic field lines are tilted down from the equator to higher latitudes. This results in the equatorial ionospheric anomaly being tilted down as the plasma moves from lower latitudes to higher ones. As a result, the latitude of the TEC crest is lower than that of the $N m \mathrm{~F} 2$ crest.

\section{Summary}

Based on the TEC data from China Crustal Movement Observation Network during declining solar activity phase of 2004, the seasonal, local time, latitudinal and longitudinal variations of the TEC as well as its day-to-day variation were studied. As a whole, the seasonal variation of the ionospheric TEC shows a double-peak structure at the vernal and autumnal equinoxes, and the diurnal variation of the ionospheric TEC shows an obvious peak structure in the post noon. These peak values increased from the north to the south of China. The peak time of the diurnal variation was earlier at higher latitudes than at lower latitudes. There are small, but clear longitudinal difference in both sides of the longitudes with zero magnetic declination, which is probably caused by the 
longitude variations of both the magnetic declination and the zonal thermospheric wind.

Combining the TEC data with $N m \mathrm{~F} 2$ data deduced from the $f o \mathrm{~F} 2$ values, the day-to-day variations of the ionosphere were studied. The day-to-day variation of the ionospheric TEC was not monotonic change along latitudes. It was usually weaker in the middle of China than that in the north or south. However, all of the day-to-day variations of TEC were smaller than that of $N m \mathrm{~F} 2$ at the same position. There was also a seasonal variation with the peak values in March and July, which was not obvious for the $\mathrm{NmF}$.

The difference of the location of the TEC crest from the $N m \mathrm{~F} 2$ crest was analysed by both observation and simulation. The location of TEC crest lies in Hainan province basically and can hardly reach Guangzhou, while the crest determined by $N m \mathrm{~F} 2$ can usually reach Guangzhou. This phenomenon could be interpreted as a result of the tilt of the topside ionosphere near the anomaly crest region by equatorial fountain effects.

This work has dealt mainly with the TEC in the declining phase of the solar activity in 2004. The variations of ionospheric TEC over China need further investigation and more TEC data for a longer period of time.

Acknowledgements. We acknowledge Shanghai Astronomical Observatory, Chinese Academy of Sciences for providing the ionospheric TEC data. The SAMI2 ionosphere model was written and developed by the Naval Research Laboratory. This work is supported by Public Welfare Scientific (meteorology) Research Project (Grant No. GYHY200806072 and GYHY201106011), the National Natural Science Foundation of China (Grants No. 40890164, 40874082) and Ocean Public Welfare Scientific Research Project, State Oceanic Administration of People's Republic of China (201005017).

Topical Editor K. Kauristie thanks two anonymous referees for their help in evaluating this paper.

\section{References}

Afraimovich, E. L., Astafyeva, E. I., Oinats, A. V., Yasukevich, Yu. V., and Zhivetiev, I. V.: Global electron content: a new conception to track solar activity, Ann. Geophys., 26, 335-344, doi:10.5194/angeo-26-335-2008, 2008.

Astafyeva, E. I., Afraimovich, E. L., Oinats A. V., Yasukevich, Y. V., and Zhivetiev, I. V.: Dynamics of global electron content in 1998-2005 derived from global GPS data and IRI modeling, Adv. Space Res., 42, 763-769, 2008.

Bagiya, Mala S., Joshi, H. P., Iyer, K. N., Aggarwal, M., Ravindran, S., and Pathan, B. M.: TEC variations during low solar activity period (2005-2007) near the Equatorial Ionospheric Anomaly Crest region in India, Ann. Geophys., 27, 1047-1057, doi:10.5194/angeo-27-1047-2009, 2009.

Breed, A. M., GoodWin, G. L., and Silby, J. H.: Total electron contentm easurementisn the southernh emisphere using GPS satellites, 1991 to 1995, Radio Sci., 33, 1705-1726, 1998.
Browne, I. C., Evans, J. V., Hargreaves, J. K., and Murray, W. A. S.: Radio echoes from the moon, Proceedings of the Physical Society, 69, 901-920, 1956.

Chauhan, V., Singh, O. P., and Singh, B.: Diurnal and seasonal variation of GPS-TEC during a low solar activity preriod as observed at low latitude station Agra, India Journal of Radio \& Space Physics, 40, 26-36, 2011.

Evans, J. V.: The measurement of the electron content of the ionosphere by the lunar radio echo method, Proceedings of the Physical Society, Section B 69, 953-955, 1956.

Evans, J. V.: Some post-war developments in ground-based radiowave sounding of the ionosphere, J. Atmos. Terr. Phys, 36, 2183-2234, 1974.

Evans, J. V.: Satellite beacon contributions to studies of the structure of the ionosphere, Rev. Geophys. Space Phys., 15, 325-350, 1977.

Gupta, J. K. and Singh, L.: Long term ionospheric electron content variations over Delhi, Ann. Geophys., 18, 1635-1644, doi:10.1007/s00585-001-1635-8, 2000.

Hocke, K.: Osicillations of global mean TEC, J. Geophys. Res., 113, A04302, doi:10.1029/2007JA012798, 2008.

Hocke, K.: Reply to comment by J. T. Emmert et al. on "Oscillations of global mean TEC”, J. Geophys. Res., 114, A01310, doi:10.1029/2008JA013786, 2009.

Huang, Y. N., Cheng, K., and Chen, S. W.: Daily observations of the development of the ionosphereic quatorial anomaly by means of differential Doppler shift method, Radio Sci., 22, 433-438, 1987.

Huang, Y. N., Cheng, K., and Chen, S. W.: On the Equatorial Anomaly of the Ionospheric Total Electron Content Near the Northern Anomaly Crest Region, J. Geophys. Res., 94, 1351513525, 1989.

Huba, J. D., Joyce, G., and Fedder, J. A.: Sami2 is Another Model of the Ionosphere (SAMI2) - A new low-latitude ionosphere model, J. Geophys. Res., 105, 23035-23053, 2000.

Huo, X. L., Yuan, Y. B., and Ou, J. K.: The diurnal variations, semiannual and winter anomalies of the ionospheric TEC based on GPS data in Chinal, Progress in Nature Science, 15, 56-60, 2005.

Liang, P. H.: F2 ionization and geomagnetic latitudes, Nature, 160, 642-643, 1947.

Liu, L. B. and Chen, Y. D.: Statistical analysis of solar activity variations of total electron content derived at Jet Propulsion Laboratory from GPS observations, J. Geophys. Res., 114, A10311, doi:10.1029/2009JA014533, 2009.

Liu, L. B., Zhao, B. Q., Wan,W. X., Ning, B. Q., Zhang M. L., and He, M. S.: Seasonal variations of the ionospheric electron densities retrieved from Constellation Observing System for Meteorology, Ionosphere, and Climate mission radio occultation measurements, J. Geophys. Res., 114, A02302, doi:10.1029/2008JA013819, 2009.

Liu, R. Y., Liu, G. H., and Wu, J.: Ionospheric $f o \mathrm{~F} 2$ reconstruction and its application to the short-tern forecasting in China region, Chinese Journal of Geophysics, 51, 300-306, 2008.

Martyn, D. F.: Atmospheric tides in the ionosphere. I. Solar tides in the F2 region, Proc. R. Soc. London, Ser. A, 189, 241-260, 1947.

Martyn, D. F.: Electric currents in the ionosphere. III. Ionization drift due to winds and electric fields, Philos. Trans. R. Soc. London, Ser. A, 246, 306-320, 1953.

Nelson, G. J.: The annual and seasonal anomalies in the electron content of the ionosphere, J. Atmos. Terr. Phys., 30, 1591-1596, 
1968.

Nisbet, J. S.: Electron density distribution in the upper ionosphere from rocket measurements, J. Geophys. Res., 65, 2597-2599, 1960.

Oran, E. S., Young, T. R., Anderson, D. V., Coffey, T. P., Kepple, P. C., Ali, A. W., and Strobel, D. F.: A numerical model of the midlatitude ionosphere, NRL Memo. Rep. 2839, Naval Res. Lab., Washington, D.C., 1974.

Perevalova, N. P., Polyakova, A. S., and Zalizovski, A. V.: Diurnal variations of the total electron content under quiet heligeomagnetic condictions, J. Atmo. Terr. Phys., 72, 997-1007, 2010.

Richards, P. G., Fennelly, J. A., and Torr, D. G.: EUVAC: A solar EUV flux model for aeronomic calculations, J. Geophys. Res., 99, 8981-8992, 1994.

Rama Rao, P. V. S., Gopi Krishna, S., Niranjan, K., and Prasad, D. S. V. V. D.: Temporal and spatial variations in TEC using simultaneous measurements from the Indian GPS network of receivers during the low solar activity period of 2004-2005, Ann. Geophys., 24, 3279-3292, doi:10.5194/angeo-24-3279-2006, 2006.

Stamatis, S. K., Xenos, T. D., Polimeris, K. V., and Stergiou, D.: TEC and $f o F 2$ variations: preliminary results, Ann. Geophys., 47, 1325-1332, 2004, http://www.ann-geophys.net/47/1325/2004/.

Strobel, D. F., Young, T. R., Meier, R. R., Coffey, T. P., and Ali, A. W.: The nighttime ionosphere: $\mathrm{E}$ region and lower $\mathrm{F}$ region, J. Geophys. Res., 79, 3171-3178, 1974.

Tsai, H. F., Liu, J. Y., Tsai, W. H., and Liu, C. H.: Seasonal variations of the ionospheric total electron content in Asian equatorial anomaly regions, J. Geophys. Res., 106, 30363-30369, 2001.

V. Appleton, E.: Two Anomalies in the ionosphere, Nature, 157, 691-691, 1946.
Wu, S., Zhang, K., Yuan, Y., and Wu, F.: Spatio-temporal Characteristics of the Ionospheric TEC Variation for GPSnet-based Realtime Positioning in Victoria, J. Global Positioning Systems, 5, 52-57, 2006.

Xiao, Z. and Zhang, D. H.: An approach to study the day-to-day variations of ionospheric TEC directly by GPS time-delay signals, Chinese Journal of Space Science, 20, 97-102, 2000.

Xue, J. C., Song, S. L., Zhu, W. Y., and Lu, X. S.: A study on the reliability of the ionopheric VTEC and satellite DCB derived from a regional GPS network, Chinese Astronomy and Astrophysics, 36, 73-85, 2012.

Yu, T., Wan, W. X., and Liu, L. B.: Using IGS data to analysis the global TEC annual and semiannual variation, Chinese Journal of Geophysics, 49, 943-949, 2006.

Zhang, H. P., Chi, C., and Tang, W. M.: United solution to polynomial VTEC modeling and DCB analysis using ground-based GPS observations. Geomatics and Information Science of Wuhan University, 33, 805-809, 2008.

Zhang, S.-R., Holt, J. M., van Eyken, A. P., McCready, M., Amory-Mazaudiar, C., Fukao, S., and Sulzer, M.: Ionospheric local model and climatology from long-term databases of multiple iocoherent scatter radars, Geophys. Res. Lett., 32, L20102, doi:10.1029/2005GL023603, 2005.

Zhang, S.-R., Foster, J. C., Coster, A. J., and Erickson, P. J.: East-West Coast differences in total electron content over the continental US, Geophys. Res. Lett., 38, L19101, doi:10.1029/2011GL049116, 2011.

Zhang, S. R., Coster, A., Holt, J., Foster, J., and Erickson, P.: Ionospheric longitudinal variations at midlatitudes: Incoherent scatter radar observation at Millstone Hill, Sci. China Tech. Sci., 55, 1153-1160, doi:10.1007/s11431-012-4784-y, 2012. 